\title{
Magnolol inhibits angiogenesis by regulating ROS-mediated apoptosis and the PI3K/AKT/mTOR signaling pathway in $\mathrm{mES} / \mathrm{EB}$-derived endothelial-like cells
}

\author{
GI DAE KIM ${ }^{1}$, JEDO OH ${ }^{1}$, HYEN-JOO PARK ${ }^{1}$, KIHWAN BAE ${ }^{2}$ and SANG KOOK LEE ${ }^{1}$ \\ ${ }^{1}$ Natural Products Research Institute, College of Pharmacy, Seoul National University, Gwanak-gu, \\ Seoul 151-742; ${ }^{2}$ College of Pharmacy, Chungnam National University, Daejon, Republic of Korea
}

Received March 16, 2013; Accepted May 2, 2013

DOI: $10.3892 /$ ijo.2013.1959

\begin{abstract}
Magnolol, a neolignan from the traditional medicinal plant Magnolia obovata, has been shown to possess neuroprotective, anti-inflammatory, anticancer and antiangiogenic activities. However, the precise mechanism of the anti-angiogenic activity of magnolol remains to be elucidated. In the present study, the anti-angiogenic effect of magnolol was evaluated in mouse embryonic stem (mES)/embryoid body (EB)-derived endothelial-like cells. The endothelial-like cells were obtained by differentiation from $\mathrm{mES} / \mathrm{EB}$ cells Magnolol $(20 \mu \mathrm{M})$ significantly suppressed the transcriptional and translational expression of platelet endothelial cell adhesion molecule (PECAM), an endothelial biomarker, in mES/ EB-derived endothelial-like cells. To further understand the molecular mechanism of the suppression of PECAM expression, signaling pathways were analyzed in the $\mathrm{mES} /$ EB-derived endothelial-like cells. Magnolol induced the generation of reactive oxygen species (ROS) by mitochondria, a process that was associated with the induction of apoptosis as determined by positive Annexin $\mathrm{V}$ staining and the activation of cleaved caspase-3. The involvement of ROS generation by magnolol was confirmed by treatment with an antioxidant, $\mathrm{N}$-acetyl-cysteine (NAC). NAC inhibited the magnolol-mediated induction of ROS generation and suppression of PECAM expression. In addition, magnolol suppressed the activation of MAPKs (ERK, JNK and p38) and the PI3K/AKT/mTOR signaling pathway in $\mathrm{mES} / \mathrm{EB}$-derived endothelial-like cells. Taken together, these findings demonstrate for the first time that the anti-angiogenic activity of magnolol may be associated with ROS-mediated apoptosis and the suppression of
\end{abstract}

Correspondence to: Dr Sang Kook Lee, College of Pharmacy, Natural Products Research Institute, Seoul National University, 1 Gwanak-ro, Gwanak-gu, Seoul 151-742, Republic of Korea E-mail: sklee61@snu.ac.kr

Key words: magnolol, anti-angiogenesis, platelet endothelial cell adhesion molecule, PI3K/AKT/mTOR, mouse embryonic stem cells the PI3K/AKT/mTOR signaling pathway in $\mathrm{mES} / \mathrm{EB}$-derived endothelial-like cells.

\section{Introduction}

Angiogenesis, the formation of new microvessels from the pre-existing blood vasculature, is a highly regulated process that involves the activation, growth and migration of endothelial cells and capillary morphogenesis $(1,2)$. Although angiogenesis is an essential process in embryonic vascular development, organ regeneration and wound healing, a variety of pathological diseases, including cancer, rheumatoid arthritis and diabetic retinopathy, also involve angiogenic events $(1,3)$. Therefore, the identification of anti-angiogenic agents with new mechanisms of action would be an attractive strategy for studying angiogenic processes and providing potential lead candidates for the development of new drugs associated with angiogenesis (4). There is increasing evidence that reactive oxygen species (ROS) are involved in the regulation of angiogenesis. Although high levels of ROS may result in oxidative damage to various cellular components and, finally, in cell apoptosis (5), low levels of ROS have been demonstrated to be involved in signal transduction cascades that regulate endothelial cell growth, migration and organization into tubular network structures, which are critical steps in angiogenesis $(6,7)$. The ROS-induced apoptotic pathway is also considered the intrinsic or mitochondrial pathway, in which intrinsic death stimuli directly or indirectly activate the mitochondrial pathway (8). The mitogen-activated protein kinase (MAPK) and AKT/mTOR signaling pathways play important roles in the regulation of many cellular processes, including cell growth and proliferation, differentiation and apoptosis (9). Previous studies have also indicated that ROS can induce or mediate the activation of MAPK signaling pathways (10) and MAPK signaling proteins are involved in growth arrest and apoptosis via ROS generation (11).

Embryonic stem (ES) cells are pluripotent cells established from the inner cell mass of blastocysts and have the potential to differentiate into many cell types, such as hematopoietic cells, neuronal cells, cardiomyocytes, muscle cells, epithelial cells and endothelial cells $(12,13)$. Therefore, ES cells are considered a useful tool for the study of angiogenesis, 
including the processes of angioblast differentiation, proliferation, migration, endothelial cell-cell adhesion and vascular morphogenesis $(12,14,15)$. One promising approach for differentiating ES cells into endothelial cells is the use of embryoid bodies (EBs), which are embryo-like aggregates of ES cells. Therefore, the ES/EB system represents a good in vitro model for the study of vasculogenesis as well as angiogenesis (16). In addition, ES-derived EB cells closely resemble their in vivo counterparts and thus provide a useful in vitro model for the study of specific cell signaling systems $(17,18)$. Recently, we also demonstrated the usefulness of mES-derived endothelial cell systems in the evaluation of the effect of 5-FU on vasculogenesis and the anti-angiogenic effects of natural product-derived compounds $(19,20)$.

Magnolol is a neolignan from the bark of Magnolia obovata Thunberg (Magnoliaceae), which has traditionally been used to treat gastrointestinal tract disorders in Asian countries $(21,22)$. A variety of pharmacological activities of magnolol have been reported, including anti-inflammatory (23), anti-oxidant (24), anticancer and anti-angiogenic effects. The anticancer activity of magnolol was found to be able to suppress the proliferation of cancer cells by inhibiting DNA synthesis and inducing apoptosis (25-27). However, the precise mechanism of action for the anti-angiogenic activity of magnolol remains to be elucidated.

In the present study, we demonstrated that magnolol might be able to suppress angiogenesis through the inhibition of ROS-mediated MAPK and AKT/mTOR signaling in mES/ EB-derived endothelial-like cells.

\section{Materials and methods}

Reagents and antibodies. 3-(4,5-Dimethylthiazol-2yl)-2,5-diphenyltetrazolium bromide (MTT), dimethyl sulfoxide (DMSO), gelatin and HRP-conjugated anti-mouse and anti-rabbit antibodies were purchased from SigmaAldrich (St. Louis, MO, USA). Collagen type I was purchased from BD Biosciences (San Jose, CA, USA). Phosphospecific anti-p38( Thr $\left.^{180} / \mathrm{Tyr}^{182}\right)$, anti-JNK( $\left.\mathrm{Thr}^{183} / \mathrm{Tyr}^{185}\right)$, anti-PI3K, anti-PDK1, anti-AKT(Ser $\left.{ }^{47}\right)$, anti-mTOR(Ser $\left.{ }^{248}\right)$, anti-p70S6K $\left(\mathrm{Thr}^{389}\right)$, anti-4EBP1( $\left.\mathrm{Thr}^{37} / \mathrm{Thr}^{46}\right)$ and procaspase-3 antibodies, the MAPK inhibitors; SB203580, PD98059 and SP600125; and the PI3K inhibitor LY294002 were purchased from Cell Signaling Technology (Danvers, MA, USA). The HRP-conjugated $\beta$-actin, phospho-ERK(Thr ${ }^{202} /$ $\mathrm{Tyr}^{204}$ ), Bcl-xL, Bax and PECAM antibodies were purchased from Santa Cruz Biotechnology (Santa Cruz, CA, USA). 2'7'-Dichlorofluorescein diacetate $\left(\mathrm{H}_{2} \mathrm{DCFDA}\right)$ and Alexa Fluor 594-labeled chicken anti-rat IgG were purchased from Molecular Probes (Invitrogen, Carlsbad, CA, USA). Magnolol (purity $>98 \%$, Fig. 1A) isolated from the bark of Magnolia obovata was provided by Dr K. Bae (28). The compound was dissolved in $100 \%$ DMSO. A $100-\mathrm{mM}$ stock solution of magnolol was prepared and stored at $-20^{\circ} \mathrm{C}$ until use.

Cell culture. Mouse $\mathrm{D}_{3}$ ES cells (ATCC cat. no. CRL-1934, Rockville, MD, USA) were co-cultured with mitomycin C-treated mouse embryonic fibroblasts in high-glucose DMEM (Invitrogen) containing 10\% fetal bovine serum (Hyclone, Ogden, UT, USA), $1,000 \mathrm{U} / \mathrm{ml}$ leukemia inhibitory factor
(LIF) (Chemicon, Temecula, CA, USA) and basic ES medium components $[50 \mathrm{U} / \mathrm{ml}$ penicillin and $50 \mu \mathrm{g} / \mathrm{ml}$ streptomycin (Invitrogen), 1\% non-essential amino acids (Invitrogen) and $0.1 \mathrm{mM} \beta$-mercaptoethanol (Invitrogen)]. The hanging drop method (20 $\mu$ l per drop; $1 \times 10^{5}$ cells $\left./ \mathrm{ml}\right)$ was used to induce differentiation as previously described $(20,29)$. The EBs were formed by incubating the hanging drop cultures for 3 days. The resulting EBs were transferred onto gelatin-coated chamber slides (Nunc, Denmark) or 60-mm dishes to allow attachment. Endothelial cell differentiation was induced in EBs by switching the culture conditions to medium containing EBM-2, 5\% FBS, a growth factor cocktail and ascorbic acid (EGM2-MV Bullet kit; Lonza, Walkersville, MD, USA). The cell culture and endothelial differentiation conditions for the mES cells followed the protocol in our previous report $(20,30)$.

Growth inhibition assay. The growth inhibition activity in cultured mES-derived endothelial-like cells was determined using MTT assays as previously described (20,30). Briefly, cells were seeded at a density of 5,000 cells/well into 96-well plates. On differentiation day 10 , the cells were exposed to various concentrations of magnolol for $24 \mathrm{~h}$. After incubation, MTT solution was added and the cells were incubated for an additional $4 \mathrm{~h}$. The resulting formazan was dissolved in DMSO and the absorbance was detected at $570 \mathrm{~nm}$ with a VersaMax ELISA microplate reader (Molecular Devices, Sunnyvale, CA, USA). After treatment of cells with magnolol for $24 \mathrm{~h}$ at differentiation day 10 , the cytotoxicity of magnolol was tested using the CytoTox $96^{\circledR}$ Non-Radioactive Cytotoxicity assay (Promega, Madison, WI, USA). The effects on cell viability and the cytotoxicity activity of magnolol were calculated as percentages relative to the solvent-treated control.

Immunocytochemistry. Cells were plated onto confocal dishes and induced to differentiate into endothelial-like cells by incubation in EGM-2 medium for 10 days. The mES/EB-derived endothelial-like cells were incubated with magnolol with or without $5 \mathrm{mM}$ NAC for $24 \mathrm{~h}$. After incubation, the cells were fixed with $4 \%$ paraformaldehyde. The cells were blocked with blocking solution containing 1\% BSA/PBS for $30 \mathrm{~min}$ and then incubated with rat anti-mouse PECAM (1:200) (Santa Cruz) overnight at $4^{\circ} \mathrm{C}$. After being washed, the cells were incubated with Alexa Fluor 594-labeled chicken anti-rat IgG $(1: 1,000)$ (Invitrogen). After staining, the cover slips were mounted with medium containing DAPI (Vector Laboratories, Burlingame, CA, USA). Confocal microscopy was performed using a Zeiss Model 710 (Carl Zeiss, Jena, Germany).

RNA isolation and reverse transcription-polymerase chain reaction $(R T-P C R)$. Cells were dissolved using TRIzol ${ }^{\circledR}$ (Invitrogen) and total RNA was extracted according to the manufacturer's protocol. The total cellular RNA was quantified using a NanoDrop spectrophotometer (NanoDrop Technologies, Inc., Wilmington, DE, USA). Reverse transcription was performed using $2 \mu \mathrm{g}$ of purified total RNA and the SuperScript First-Strand Synthesis System (Invitrogen). The synthesized cDNAs were amplified by PCR. The primers used for RT-PCR are listed in Table I. The thermal cycling parameters were as follows: $5 \mathrm{~min}$ at $94^{\circ} \mathrm{C}, 30$ amplification 
A<smiles>C=CCc1ccc(O)c(-c2cc(CC=C)ccc2O)c1</smiles>

B

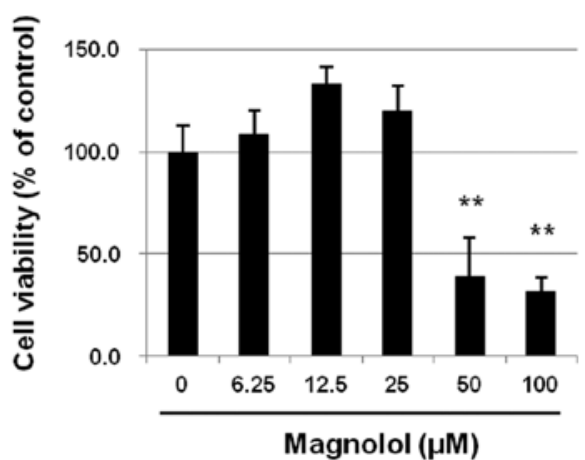

C

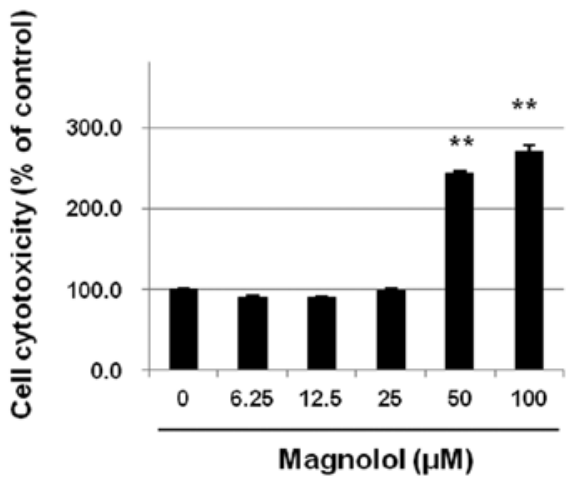

Figure 1. Effect of magnolol on cell viability and the cytotoxicity of magnolol in mES/EB-derived endothelial-like cells. (A) Chemical structure of magnolol. (B) On endothelial differentiation day $10, \mathrm{mES} / \mathrm{EB}$-derived endothelial-like cells were exposed to magnolol ( 0 - $100 \mu \mathrm{M})$ for $24 \mathrm{~h}$ and then the cell viability was measured by the MTT assay. (C) LDH leakage was evaluated after $24 \mathrm{~h}$ of treatment with magnolol (0-100 $\mu \mathrm{M})$ using an LDH assay kit. Data are presented as mean $\pm \mathrm{SD}$ in triplicate tests. ${ }^{* *} \mathrm{P}<0.01$ compared with control.

Table I. Sequences of the primer pairs of specific target genes used in RT-PCR.

\begin{tabular}{ll}
\hline Gene $\quad$ Primer sequences & $\begin{array}{c}\text { Product } \\
\text { size (bp) }\end{array}$
\end{tabular}

PECAM F 5'-CCATCATGGGAGGTGATGAA-3' R 5'-GATACGCCATGCACCTTCAC-3'

\section{GAPDH F 5'-GGAGCCAAAAGGGTCATCAT-3' R 5'-GTGATGGCATGGACTGTGGT-3'}

cycles (denaturation at $94^{\circ} \mathrm{C}$ for $30 \mathrm{sec}$, annealing at $55-60^{\circ} \mathrm{C}$ for $30 \mathrm{sec}$ and extension at $72^{\circ} \mathrm{C}$ for $30 \mathrm{sec}$ ) and a final extension at $72^{\circ} \mathrm{C}$ for $5 \mathrm{~min}$. The amplified products were separated on $1.5 \%$ agarose gels. The gels were stained with SYBR ${ }^{\circledR}$ Gold staining solution (Invitrogen) and visualized by UV transillumination (GelDoc ${ }^{\mathrm{TM}}$ XR, BioRad Molecular Imager).

Flow cytometric analysis of apoptosis. To determine the level of apoptosis following magnolol exposure for $24 \mathrm{~h}$ during the differentiation of mES cells into endothelial cells, the Annexin V-fluorescein isothiocyanate (FITC) apoptosis detection kit (BD Pharmingen) was used. In this assay, Annexin V-FITC binds to phosphatidylserine, which translocates to the outer leaflet of the plasma membrane during the early stages of cell apoptosis. Therefore, the apoptotic cells were specifically stained with Annexin V-FITC, whereas the necrotic cells were doubly stained with both Annexin V-FITC and PI. The cells were suspended in binding buffer at a final cell concentration of $1 \times 10^{5}$ cells $/ \mathrm{ml}$ and incubated with both Annexin V-FITC and PI for $25 \mathrm{~min}$ in the dark. The DNA contents of the stained cells were analyzed using CellQuest Software and a FACS Vantage SE flow cytometer (BectonDickinson, Germany).

Quantification of reactive oxygen species production. The intracellular ROS levels were measured using the fluorescent dye $\mathrm{H}_{2}$ DCFDA (Molecular Probes). Cells were induced to differentiate into endothelial-like cells by incubation in EGM-2 medium for 10 days. The $\mathrm{mES} / \mathrm{EB}$-derived endothelial-like cells were incubated with magnolol for $24 \mathrm{~h}$. Then, the cells were washed twice, stained with $20 \mu \mathrm{M} \mathrm{H}_{2}$ DCFDA (Molecular Probes) for $30 \mathrm{~min}$ and washed twice. The resulting compound, $2^{\prime} 7^{\prime}$-dichlorofluorescein diacetate $\left(\mathrm{H}_{2} \mathrm{DCFDA}\right)$, reacts with ROS to form a fluorescent compound, dichlorofluorescin (DCF). The amount of intracellular DCF was measured using flow cytometer (Becton-Dickinson).

Measurement of the mitochondrial membrane potential. Rhodamine 123 was used to assess the mitochondrial membrane potential. After treatment with magnolol for $24 \mathrm{~h}$, the cells were washed with 1X PBS and incubated with $1 \mu \mathrm{l} / \mathrm{ml}$ Rhodamine 123 for $60 \mathrm{~min}$ at room temperature in 
the dark. The cells were washed with $1 \mathrm{X}$ PBS, stained with $1 \mu \mathrm{g} / \mathrm{ml}$ PI solution and analyzed by flow cytometer (BectonDickinson). In this experiment, verapamil $(20 \mu \mathrm{M})$ was used as a positive control.

Western blot analysis. Cells were treated with magnolol for $24 \mathrm{~h}$. Harvested cells were lysed in protein extraction solution (Intron Biotechnology, Inc., Kyunggi, Korea) containing protease inhibitors and phosphatase inhibitors for $10 \mathrm{~min}$ at $4^{\circ} \mathrm{C}$. The total protein concentration in the supernatants was measured by the Bradford assay. After heating at $95^{\circ} \mathrm{C}$ for $5 \mathrm{~min}$, total protein samples $(40 \mu \mathrm{g})$ were subjected to $6-15 \%$ SDS-PAGE. The proteins were transferred onto PVDF membranes (Millipore, Bedford, MA, USA) at $100 \mathrm{~V}$ for $60-100 \mathrm{~min}$. The membranes were incubated with 5\% BSA in TBST (TBS with $0.05 \%$ Tween-20) for $30 \mathrm{~min}$ at room temperature and then with primary antibodies diluted (1:200-1:1,000) in 5\% BSA in TBST overnight at $4^{\circ} \mathrm{C}$. The membranes were washed three times with TBST and incubated with the corresponding secondary antibodies. Protein bands were detected using an enhanced chemiluminescence detection kit (Intron Biotechnology, Inc.) and a LAS-1000 Imager (Fuji Film Corp., Tokyo, Japan).

3-Dimensional type I collagen sprouting angiogenesis model. The three-dimensional tube formation and sprouting angiogenesis model were performed in type I collagen $(16,20,31)$. Briefly, EBs were formed by incubating hanging drop cultures for 3 days and then the EBs were cultured in suspension in EGM-2 medium for 7 days. The EBs were embedded in type I collagen and incubated in EGM-2 medium at $37^{\circ} \mathrm{C}$. Vascular sprouting was induced by incubation with magnolol for 4 days. The morphology of the vascular sprouts was analyzed using a phase contrast microscope (Nikon, Eclipse TE 2000-U, Tokyo, Japan).

Statistical analyses. Data are presented as the mean \pm SD for the indicated number of independently performed experiments. Statistical significance $(\mathrm{P}<0.05)$ was determined using Student's t-test for paired data. Statistical calculations were performed using SPSS for Windows Version 10.0 (SPSS, Chicago, IL, USA).

\section{Results}

Effects of magnolol on the growth of $m E S / E B$-derived endothelial-like cells. To determine whether magnolol affects the growth of mES/EB-derived endothelial-like cells, mES/ EB-derived differentiated cells (differentiation day 10) were treated with magnolol $(0-100 \mu \mathrm{M})$ for $24 \mathrm{~h}$ and then cell growth and cytotoxicity were analyzed using the MTT and LDH leakage assays, respectively. As shown in Fig. 1B, the growth inhibition effect of magnolol on the differentiated cells was concentration-dependent. The relatively low concentrations of magnolol $(\leq 25 \mu \mathrm{M})$ did not inhibit the growth of the endothelial cells, but concentrations of magnolol $>50 \mu \mathrm{M}$ significantly inhibited the growth of these cells $(\mathrm{P}<0.01)$. Further experiments confirmed that the growth inhibition activity of concentrations $>50 \mu \mathrm{M}$ magnolol was associated with the level of cytotoxicity determined by the LDH leakage assay (Fig. 1C).
Inhibition of vessel formation in the $m E S / E B$-derived endothelial-like cells by magnolol. Platelet endothelial cell adhesion molecule (PECAM) is considered a cell surface marker for endothelial cells during angiogenesis because PECAM is expressed by endothelial cells and hematopoietic cells (32). To determine whether magnolol inhibits microvessel formation in the mES/EB-derived endothelial-like cells, the cells were treated with magnolol $(0-20 \mu \mathrm{M})$ for $24 \mathrm{~h}$ and then the expression of the endothelial biomarker PECAM was analyzed. As shown in Fig. 2A, the differentiated (day 10) mES/EB-derived cells exhibited remarkable expression of PECAM, but treatment with magnolol suppressed the mRNA expression of PECAM in a concentration-dependent manner. Magnolol also markedly suppressed the expression of the PECAM protein (Fig. 2B), indicating that magnolol significantly suppressed the expression of PECAM at both the mRNA and protein levels $(\mathrm{P}<0.05, \mathrm{P}<0.01$, respectively). The effect of magnolol on the expression of PECAM was also assessed using immunofluorescence in a two-dimensional (2-D) culture of mES/EB-derived differentiated cells. As shown in Fig. 2C, the microvessels generated from the differentiation of $\mathrm{mES} /$ EB-derived cells clearly expressed PECAM, but treatment with magnolol $(20 \mu \mathrm{M})$ significantly suppressed the expression of PECAM in the differentiated endothelial cells. These results suggest that the anti-angiogenic activity of magnolol is associated with the suppression of PECAM expression. The anti-angiogenic activity of magnolol was also assessed based on the inhibition of vascular tube formation in a three-dimensional (3-D) collagen gel system. In this experiment, vascular tube formation was induced by incubating mES-derived EBs in a type I collagen gel containing EGM-2 medium as previously described by Kim et al (20). As shown in Fig. 2D-a, the morphology of the vascular sprouts formed by EB-derived endothelial-like cells was observed after 4 days of induction. Accelerated vascular tube sprouting and an extensive network of cellular outgrowths were observed in the vehicle-treated control cells (Fig. 2D-a) and magnolol effectively blocked tube sprouting and the formation of cellular networks (Fig. 2D-b and $-\mathrm{c}$ ). These findings suggest that magnolol inhibits vessel formation in $\mathrm{mES} / \mathrm{EB}$-derived endothelial-like cells in both 2-D and 3-D culture systems.

Induction of apoptosis by magnolol. We next determined whether the inhibition of both tube sprouting and the formation of cellular networks by magnolol is associated with apoptosis in $\mathrm{mES} / \mathrm{EB}$-derived endothelial-like cells. Flow cytometric analysis revealed that magnolol treatment resulted in Annexin V-positive cells in a concentrationdependent manner (Fig. 3A). In particular, the percentage of apoptotic cells among the cells treated with $20 \mu \mathrm{M}$ magnolol $(18.7 \%)$ was significantly higher than the percentage of the vehicle-treated control cells $(2.6 \%)(\mathrm{P}<0.01)$. To confirm the association between magnolol treatment and apoptosis, the effects of magnolol on the modulation of apoptotic regulatory molecules were evaluated. As shown in Fig. 3B, the proapoptotic protein Bax was upregulated and the anti-apoptotic protein Bcl-xL was downregulated by magnolol treatment. In addition, the activation of procaspase- 3 was also induced by magnolol, as confirmed by the increase in the intensity of the cleaved caspase- 3 band along with the decrease in the inten- 
A

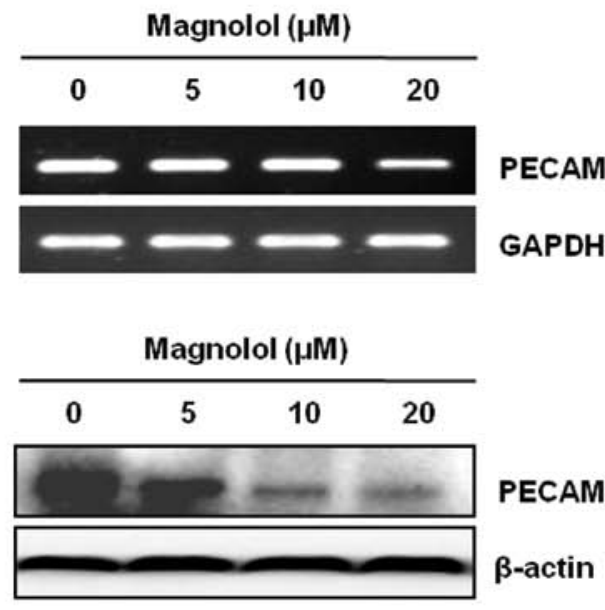

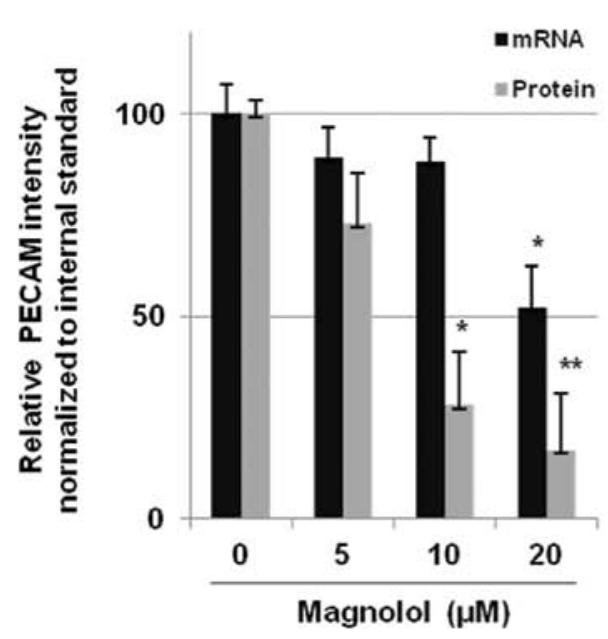

c
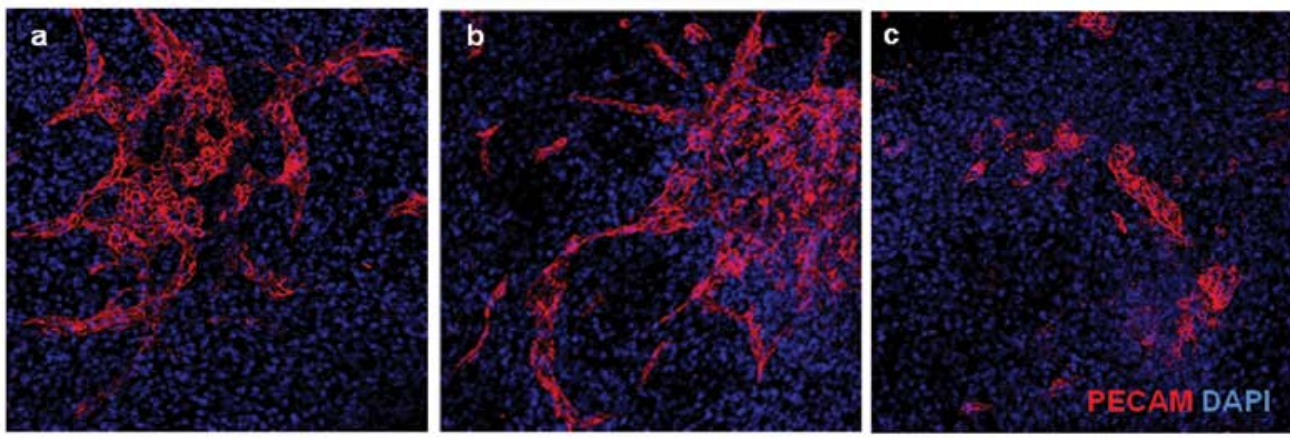

D

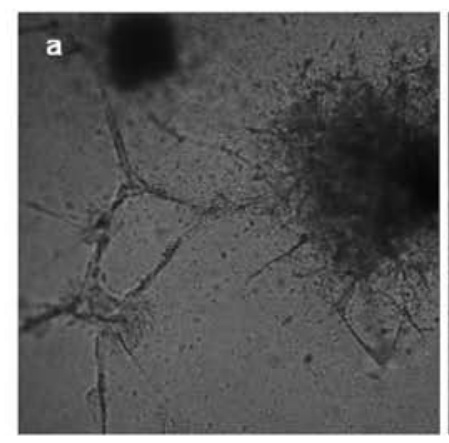

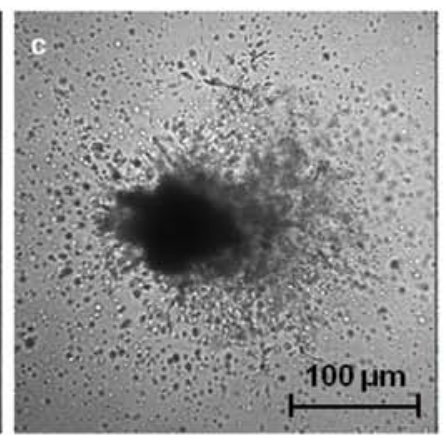

Figure 2. Effect of magnolol on the vascular sprouting of endothelial-like cells derived from mES/EBs. The EBs were differentiated into endothelial cells in EGM-2 containing supplements for 10 days and then treated with magnolol $(0-20 \mu \mathrm{M})$ for $24 \mathrm{~h}$. The levels of PECAM mRNA (A) and protein (B) in mES/EB-derived endothelial-like cells were determined by RT-PCR and western blot analysis, respectively. (C) mES/EB-derived endothelial-like cells were immunofluorescently stained with an antibody directed against the endothelial cell biomarker PECAM. Control (a), $5 \mu \mathrm{M}$ magnolol (b) and $20 \mu \mathrm{M}$ magnolol (c). Magnification, x100. (D) After being cultured in hanging drops for 3 days, EBs derived from mES cells were cultured in suspension for 7 days. The EBs embedded in collagen gels were treated with magnolol for 4 days. The morphology of the endothelial sprouts of EB-derived endothelial-like cells in the control (a) and magnolol-treated samples (b, $5 \mu \mathrm{M}$; and c, $20 \mu \mathrm{M}$ ) after 4 days of secondary culture in collagen gels. Values indicate the mean \pm SD in triplicate tests. The values marked with an asterisk are significantly different from control values, ${ }^{\prime} \mathrm{P}<0.05 ;{ }^{* *} \mathrm{P}<0.01$ compared with control. Magnification, $\mathrm{x} 40$.

sity of the procaspase- 3 band in the western blotting. These findings suggest that magnolol may induce apoptosis of mES/ EB-derived endothelial-like cells by upregulating the proapoptotic protein Bax and subsequently activating caspase-3.

Effects of magnolol on ROS production and the mitochondrial membrane potential. To further investigate whether the generation of intracellular ROS is involved in the induction of apoptosis by magnolol, the effects of magnolol on the ROS levels were determined using an oxidant-sensitive fluorescent dye in $\mathrm{mES} / \mathrm{EB}$-derived endothelial-like cells. Consistent with previous reports $(33,34)$, endogenous production of ROS was detected in mES/EB-derived endothelial-like cells. As shown in Fig. 4A, however, magnolol $(20 \mu \mathrm{M})$ significantly increased the intracellular ROS levels (cells exhibited much higher fluorescence intensities) relative to those of the vehicletreated control cells $(\mathrm{P}<0.01)$. We next examined whether the induction of ROS production by magnolol was related to the modulation of the mitochondrial membrane potential in the cells. As shown in Fig. 4B, the active accumulation of Rhodamine 123 was detected in the control cells and the positive control (verapamil-treated) cells. However, treatment 
Magnolol $(\mu \mathrm{M})$

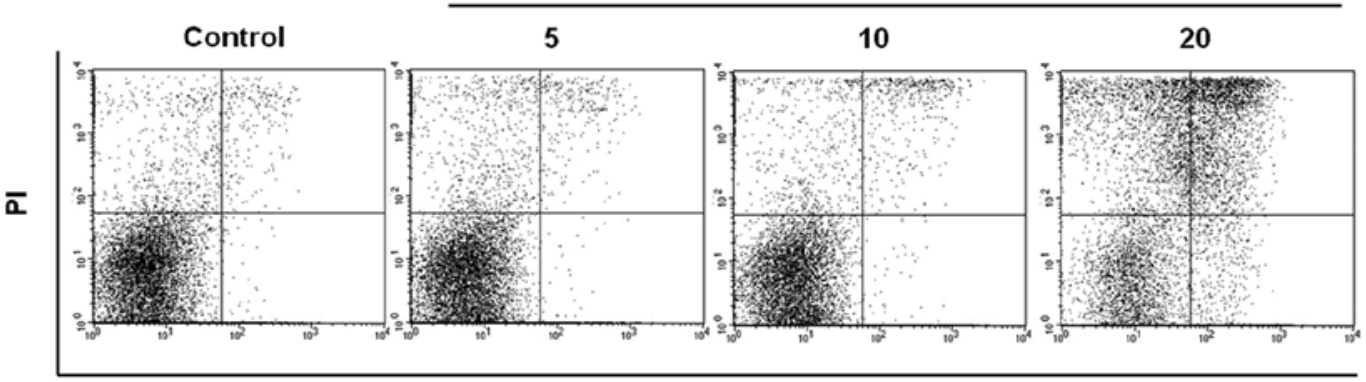

Annexin V-FITC

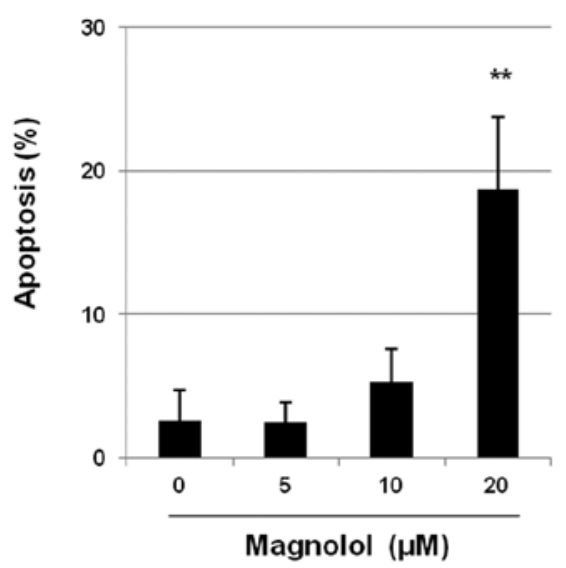

B

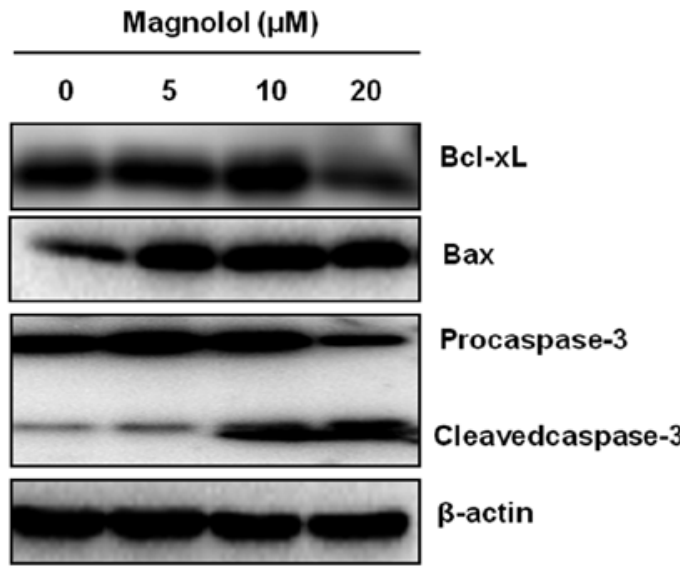

Figure 3. Effect of magnolol on the induction of apoptosis in mES/EB-derived endothelial-like cells. (A) The endothelial differentiated cells were treated with magnolol $(0,5,10$ and $20 \mu \mathrm{M})$ for $24 \mathrm{~h}$, stained with Annexin V and propidium iodide (PI) and analyzed on a FACSCalibur flow cytometer. (B) The expression of pro-apoptotic/anti-apoptotic proteins in mES-derived endothelial-like cells was analyzed by western blotting. $\beta$-actin was used as an internal control. Data are presented as mean $\pm \mathrm{SD}$ in triplicate tests. ${ }^{* *} \mathrm{P}<0.01$ compared with control.

with magnolol $(20 \mu \mathrm{M})$ remarkably decreased the uptake of Rhodamine 123 dye in the cells, suggesting that magnolol affects the mitochondrial membrane potential as the result of mitochondrial dysfunction caused by oxidative stress. In addition, the involvement of oxidative stress induced by magnolol in vasculogenesis was also confirmed using the antioxidant N-acetyl-L-cysteine (NAC). As shown in Fig. 4C, the suppression of PECAM expression by magnolol $(20 \mu \mathrm{M})$ was recovered by co-treatment with NAC (5 mM) and magnolol in $\mathrm{mES} / \mathrm{EB}$-derived endothelial-like cells. These findings suggest that oxidative stress induced by magnolol in part triggers apoptosis as the result of mitochondrial dysfunction in $\mathrm{mES} / \mathrm{EB}$-derived endothelial-like cells.

Effects of magnolol on MAP kinase signaling. To further clarify whether the anti-angiogenic activity of magnolol is also mediated by signaling molecules related to cell proliferation, the effects of magnolol on MAPK signaling were determined in $\mathrm{mES} / \mathrm{EB}$-derived endothelial-like cells. Magnolol downregulated the activation of MAP kinases including ERK, JNK and p38 in mES/EB-derived endothelial-like cells (Fig. 5A). The association with MAPK signaling was also confirmed using the inhibitors PD98059 (ERK inhibitor), SP600125 (JNK inhibitor) and SB203580 (p38 inhibitor). As shown in Fig. 5B-D, magnolol suppressed the activation of MAPKs to an extent similar to that of each kinase inhibitor in $\mathrm{mES} /$
EB-derived endothelial-like cells. In addition, the co-treatment of cells with an ERK or JNK inhibitor and magnolol $(20 \mu \mathrm{M})$ enhanced the suppression of ERK and JNK activation.

Effects of magnolol on the PI3K/AKT/mTOR signaling pathway. Accumulating evidence suggests that the PI3K/AKT/ mTOR signaling pathway plays an important role in the vasculogenesis and angiogenesis of endothelial cells $(35,36)$. To investigate whether magnolol affects this signaling pathway, the constitutive activation of PI3K/AKT/mTOR expression was evaluated in mES/EB-derived endothelial-like cells. As shown in Fig. 6A, the constitutive activation of both PI3K and PDK was downregulated by treatment with magnolol in a concentration-dependent manner. In addition, the downregulation of AKT activation by magnolol led to the subsequent suppression of signaling by mTOR and its downstream effectors, including S6K and 4EBP1, in mES/EB-derived endothelial-like cells. We also found that co-treatment with the AKT inhibitor LY294002 and magnolol synergistically suppressed the activation of AKT (Fig. 6B).

\section{Discussion}

Because angiogenesis is associated with many pathological diseases, including cancer, diabetic retinopathy and arthritis, anti-angiogenic agents with unique mechanisms of action 
A
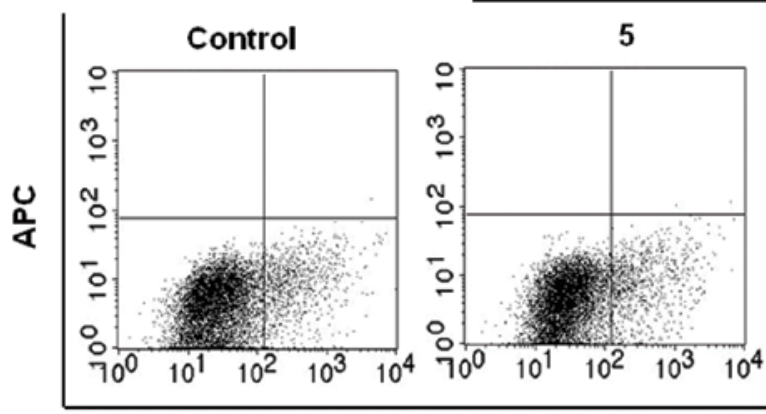

Magnolol ( $\mu \mathrm{M})$

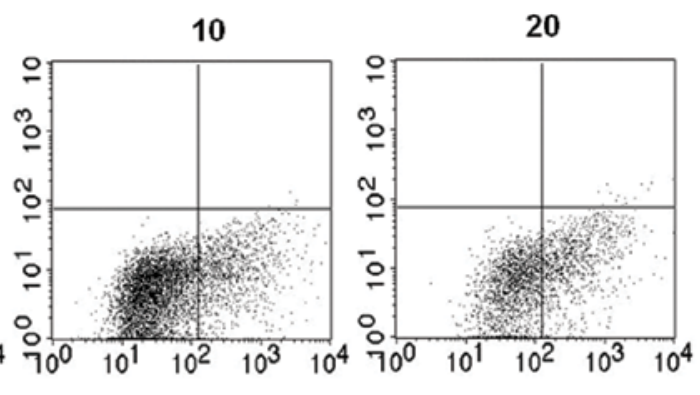

(FITC)

B

Control
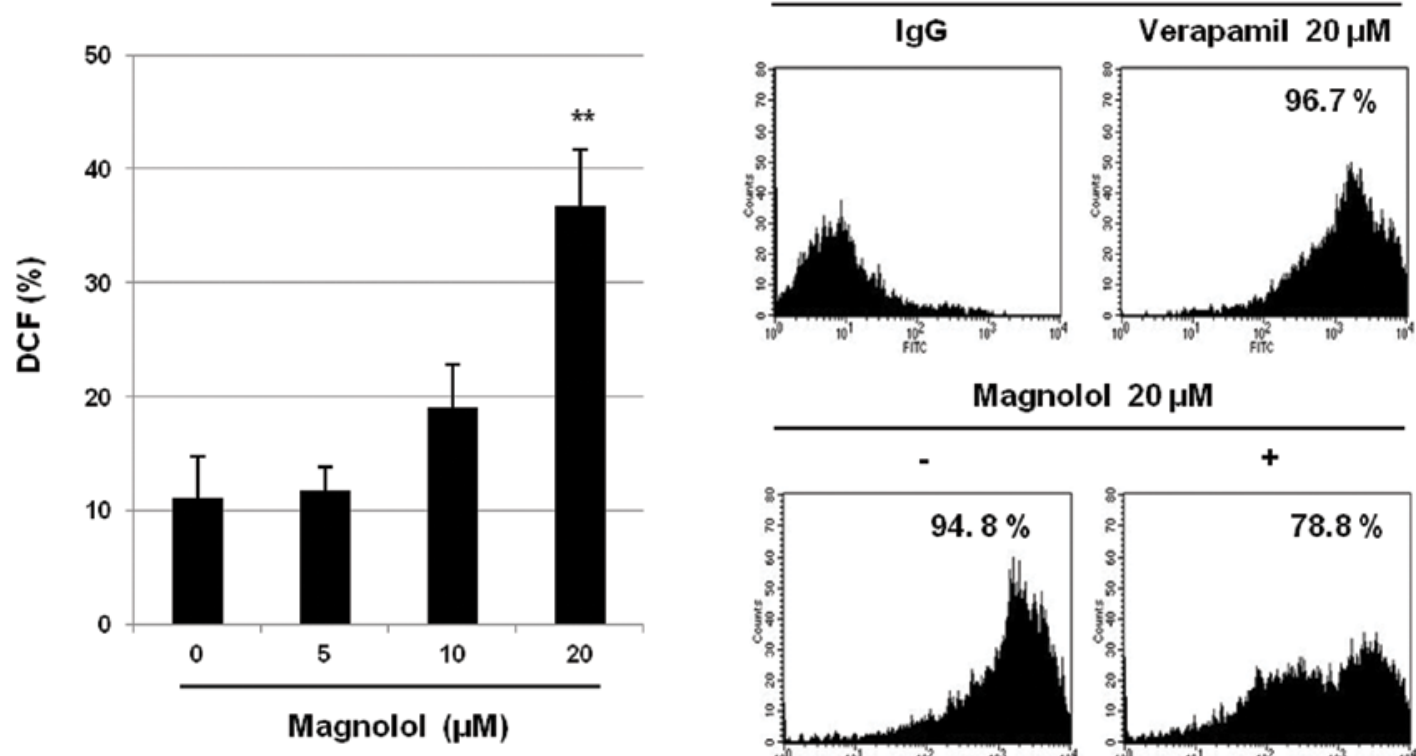

Magnolol $20 \mu \mathrm{M}$

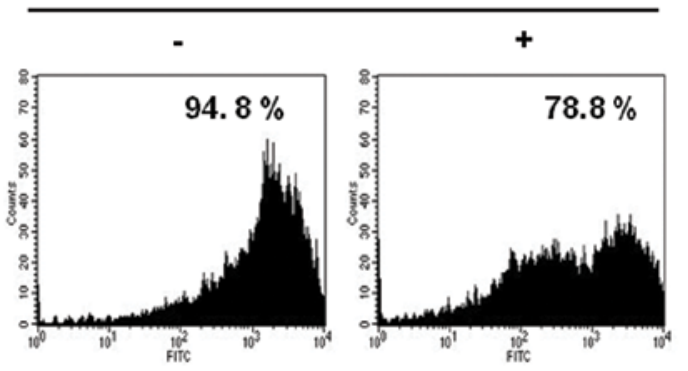

Magnolol $20 \mu \mathrm{M}$

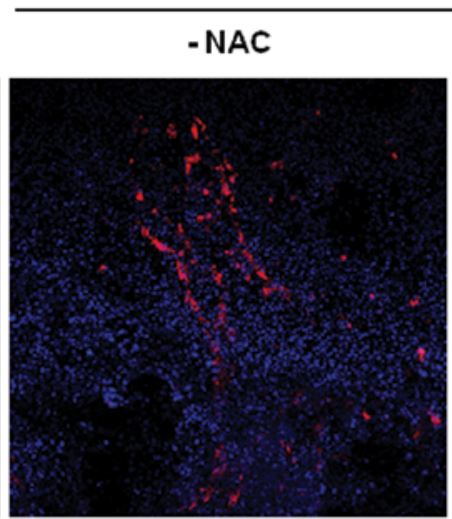

+ NAC

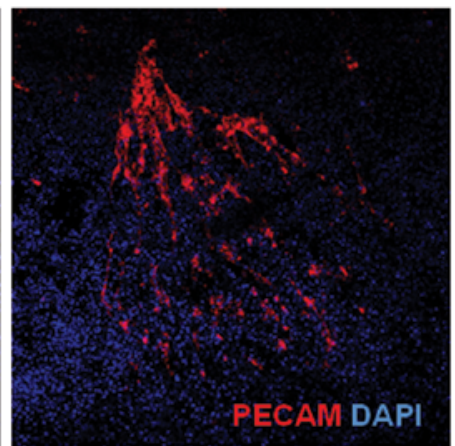

Figure 4. Effect of magnolol on the mitochondrial membrane potential and ROS production in mES/EB-derived endothelial-like cells. (A) Reactive oxygen species (ROS) generation was quantified using $\mathrm{H}_{2}$ DCFDA in mES/EB-derived endothelial-like cells exposed to magnolol (0-20 $\left.\mu \mathrm{M}\right)$ for $24 \mathrm{~h}$. (B) After treatment with magnolol or verapamil (positive control) for $24 \mathrm{~h}$, the cells were incubated with Rhodamine 123 and then analyzed by flow cytometer. (C) Cells were treated with magnolol in the absence or presence of $5 \mathrm{mM}$ NAC for $24 \mathrm{~h}$ and the cells were stained with PECAM and then analyzed by confocal microscopy. Values indicate the mean $\pm \mathrm{SD}$ in triplicate tests. The values marked with an asterisk are significantly different from control values; ${ }^{* *} \mathrm{P}<0.01$. Magnification, x60.

might be potential candidates to treat or prevent these diseases $(37,38)$. In the present study, we demonstrated that magnolol exerts an anti-angiogenic activity involving ROS-mediated apoptosis and the suppression of the AKT/mTOR signaling pathway in $\mathrm{mES} / \mathrm{EB}$-derived endothelial-like cells. A variety of assay systems have been developed to evaluate the antiangiogenic activity of test compounds $(15,20)$. In particular, the utility of stem cells has been highlighted in recent reports 
A

\begin{tabular}{|c|c|c|c|c|}
\hline \multicolumn{4}{|c|}{ Magnolol ( $\mu \mathrm{M})$} & \\
\hline $\mathbf{0}$ & 5 & 10 & 20 & \multirow[b]{2}{*}{ p-ERK $\left(\mathrm{Thr}^{202} / \mathrm{Tyr}^{204}\right)$} \\
\hline$\overline{\overline{-}}$ & $=$ & - & & \\
\hline & $\overline{5}$ & 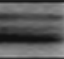 & - & PJNK(Thr ${ }^{\left.183 / T_{y r}{ }^{185}\right)}$ \\
\hline 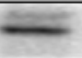 & 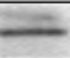 & - & 3 & p-p38(Thr ${ }^{180} /$ Tyr $\left.^{182}\right)$ \\
\hline 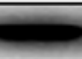 & & & & $\beta$-actin \\
\hline
\end{tabular}

B
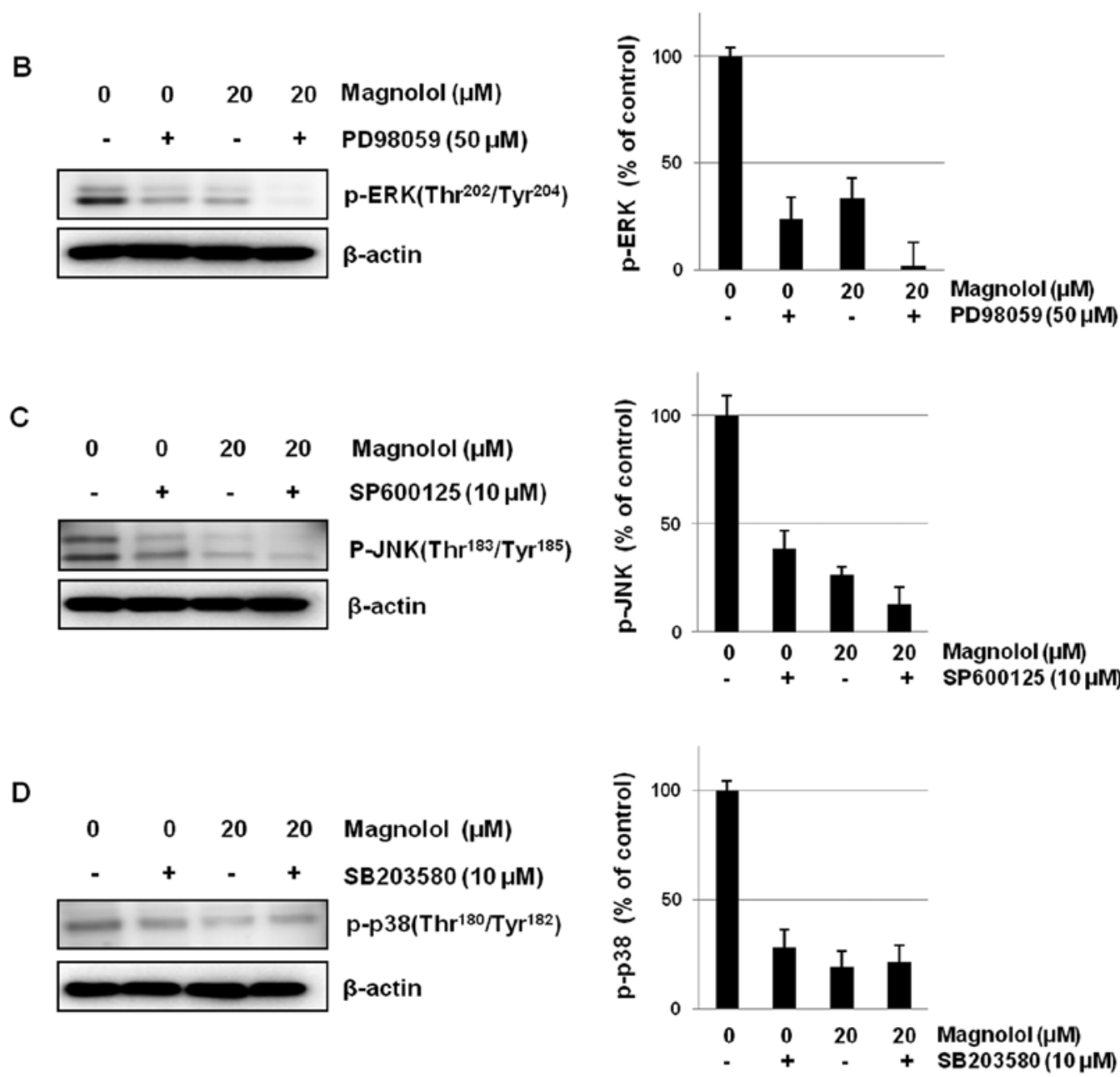

Figure 5. Effect of magnolol on the MAPK signaling pathways in mES/EB-derived endothelial-like cells. (A) Endothelial differentiated cells were treated with magnolol $(0,5,10$, or $20 \mu \mathrm{M})$ for $24 \mathrm{~h}$. Protein samples $(40 \mu \mathrm{g})$ were subjected to $10 \%$ SDS-PAGE and phosphorylated ERK, JNK and p38 were detected by western blotting. (B-D) The cells were treated with magnolol in combination with MAPK inhibitors and then the activation of ERK, JNK and p38 was detected by western blotting. $\beta$-actin was used as an internal control. Values indicate the mean $\pm \mathrm{SD}$ in triplicate tests.

$(14,15)$. Recently, we also employed mouse embryonic stem cells and demonstrated that $\mathrm{mES} / \mathrm{EB}$-derived endothelial-like cells are a useful in vitro model system for the evaluation of the anti-angiogenic activity of natural products (20). Established 2-D and 3-D culture systems using mES/EB-derived endothelial-like cells were used to assess the characteristics of endothelial cells based on the expression of PECAM and the formation of vascular networks. Magnolol effectively inhibited vascular tube formation and suppressed PECAM expression and vessel sprouting in the established endothelial cell systems.
The induction of apoptosis is considered a plausible antiangiogenic mechanism (39-41). In the present study with mES-derived EBs, we found that magnolol might be able to induce apoptosis in mES/EB-derived endothelial-like cells. The induction of apoptosis by magnolol was confirmed by the increased percentage of Annexin V-positive cells and the enhanced expression of the pro-apoptotic protein Bax. These events subsequently activated caspase-3, thus leading to the induction of apoptosis in the endothelial-like cells (Fig. 3). These findings suggest that the induction of apoptosis by magnolol is in part associated with its anti-angiogenic activity. 
A

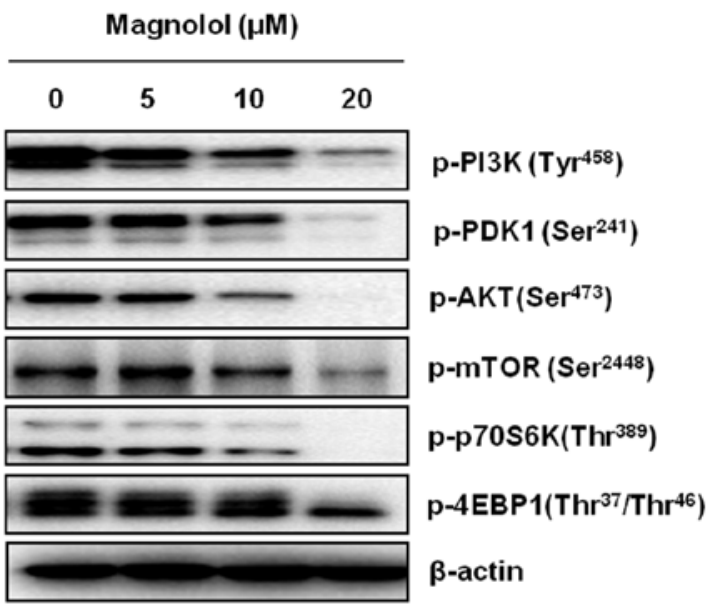

B
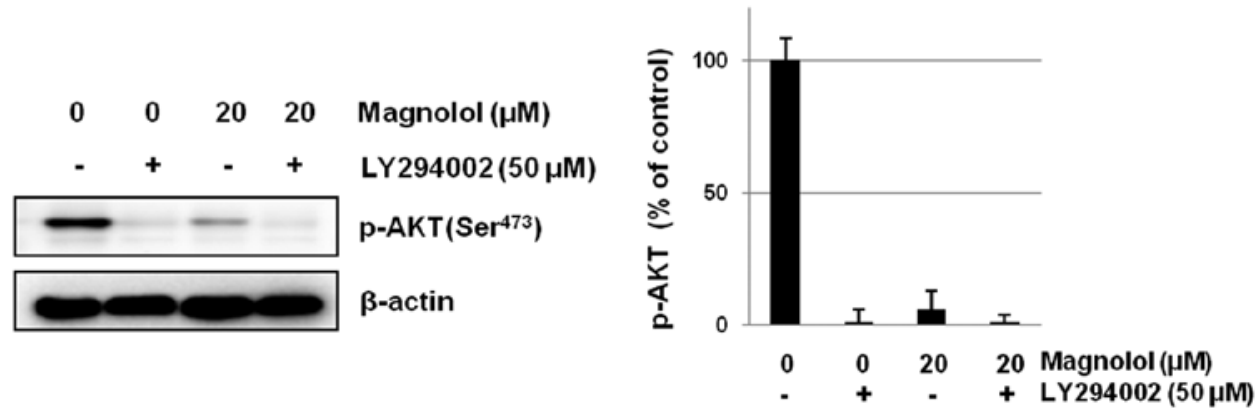

Figure 6. Effects of magnolol on the PI3K/AKT/mTOR signaling pathway in mES/EB-derived endothelial-like cells. (A) Endothelial differentiated cells were treated with magnolol $(0,5,10$, or $20 \mu \mathrm{M})$ for $24 \mathrm{~h}$. Protein samples $(40 \mu \mathrm{g})$ were subjected to 6-15\% SDS-PAGE and phosphorylated PI3K, p-PDK1, p-AKT, p-mTOR, p-p70S6K and p-4EBP1 were detected by western blotting. (B) The cells were treated with magnolol in combination with the PI3K inhibitor LY294002 and then the level of p-AKT was detected by western blotting. $\beta$-actin was used as an internal control. Values indicate the mean \pm SD in triplicate tests.

Accumulating evidence suggests that reactive oxygen species (ROS) are important mediators in apoptosis. Increased intracellular levels of ROS lead to the activation of apoptosis (42). Based on the finding that magnolol induces apoptosis in $\mathrm{mES} /$ EB-derived endothelial-like cells, the association between ROS and the anti-angiogenic activity of magnolol was determined. The cells were analyzed using an oxidant-sensitive fluorescence dye $\left(\mathrm{H}_{2} \mathrm{DCFDA}\right)$ and magnolol treatment $(20 \mu \mathrm{M})$ significantly enhanced the production of intracellular ROS in $\mathrm{mES} / \mathrm{EB}$-derived differentiated endothelial-like cells. These results indicate that the apoptosis induced by magnolol is due in part to the increased intracellular levels of ROS in the cells. In addition, mitochondria play a crucial role in metabolism and the cell cycle and they coordinate extrinsic and intrinsic signals that affect proliferation, differentiation and cell death. Mitochondria are the major organelles that produce intracellular ROS and mitochondrial dysfunction plays a key role in apoptosis (43). It is also known that increased ROS levels are able to reduce the mitochondrial membrane potential, thus leading to the activation of apoptotic pathways. The Rhodamine 123 dye was employed to assess the membrane potential and we found that magnolol effectively decreased the mitochondrial membrane potential, suggesting that the induction of apoptosis by magnolol is correlated with the increase in intracellular ROS production and the decrease in the mitochondrial membrane potential in $\mathrm{mES} / \mathrm{EB}$-derived endothelial-like cells. The association between ROS and the antiangiogenic activity of magnolol was also partly confirmed by the analysis of PECAM expression when the cells were co-treated with the antioxidant NAC. The treatment with NAC alleviated the ROS-mediated suppression of PECAM expression induced by magnolol, indicating that the anti-angiogenic potential of magnolol might be in part due to the regulation of ROS production in $\mathrm{mES} / \mathrm{EB}$-derived endothelial-like cells.

Previous studies have demonstrated that the MAPK signaling pathway is highly involved in cell growth (44) and/ or the regulation of the cell cycle (45). In our experiments, magnolol suppressed the activation of MAPKs such as ERK, JNK and p38 and these findings were confirmed using MAPK inhibitors in mES/EB-derived endothelial-like cells. It is well-known that AKT and its downstream signaling partners, including mTOR, are activated during angiogenesis (46). AKT is a serine/threonine kinase that plays a central role in a range of cellular functions, including cell growth, proliferation, migration, protein synthesis, transcription, survival and angiogenesis $(9,47)$. The mTOR kinase, a central regulator of cell metabolism, growth, proliferation and survival, is also activated during various cellular processes, such as tumor initiation, progression and angiogenesis (35). Indeed, the activation of the AKT/mTOR signaling pathway in endothelial cells promotes the survival of these cells when cultured in vitro (36). In the present study, we found that magnolol suppressed the phosphorylation of AKT, mTOR, S6K and 4EBP1 in mES/EB-derived endotheliallike cells. These suppressive effects of magnolol might be an additional mechanism of action explaining this compound's anti-angiogenic activity in $\mathrm{mES} / \mathrm{EB}$-derived endothelial-like cells. 
In conclusion, the present findings demonstrate for the first time that magnolol inhibits angiogenesis in $\mathrm{mES} / \mathrm{EB}$ derived endothelial-like cells by regulating ROS-mediated apoptosis and inhibiting the PI3K/AKT/mTOR signaling pathway.

\section{Acknowledgements}

This study was supported by the National Research Foundation grant funded by the Korean Government (MEST) (no. 20090083533).

\section{References}

1. Carmeliet $P$ and Jain RK: Molecular mechanisms and clinical applications of angiogenesis. Nature 473: 298-307, 2011.

2. Holderfield MT and Hughes CC: Crosstalk between vascular endothelial growth factor, notch and transforming growth factor-beta in vascular morphogenesis. Circ Res 102: 637-652, 2008.

3. Volz KS, Miljan E, Khoo A and Cooke JP: Development of pluripotent stem cells for vascular therapy. Vascul Pharmacol 56: 288-296, 2012

4. Xu Z, Fang S, Zuo Y, et al: Combination of pigment epitheliumderived factor with radiotherapy enhances the antitumor effects on nasopharyngeal carcinoma by downregulating vascular endothelial growth factor expression and angiogenesis. Cancer Sci 102: 1789-1798, 2011.

5. Sauer H, Gunther J, Hescheler J and Wartenberg M: Thalidomide inhibits angiogenesis in embryoid bodies by the generation of hydroxyl radicals. Am J Pathol 156: 151-158, 2000.

6. Abid MR, Kachra Z, Spokes KC and Aird WC: NADPH oxidase activity is required for endothelial cell proliferation and migration. FEBS Lett 486: 252-256, 2000.

7. van Wetering S, van Buul JD, Quik S, et al: Reactive oxygen species mediate Rac-induced loss of cell-cell adhesion in primary human endothelial cells. J Cell Sci 115: 1837-1846, 2002.

8. Turrens JF: Mitochondrial formation of reactive oxygen species. J Physiol 552: 335-344, 2003.

9. Yap TA, Garrett MD, Walton MI, Raynaud F, de Bono JS and Workman P: Targeting the PI3K-AKT-mTOR pathway: progress, pitfalls and promises. Curr Opin Pharmacol 8: 393-412, 2008.

10. McCubrey JA, Lahair MM and Franklin RA: Reactive oxygen species-induced activation of the MAP kinase signaling pathways. Antioxid Redox Signal 8: 1775-1789, 2006.

11. El-Najjar N, Chatila M, Moukadem H, et al: Reactive oxygen species mediate thymoquinone-induced apoptosis and activate ERK and JNK signaling. Apoptosis 15: 183-195, 2010.

12. Risau W, Sariola H, Zerwes HG, et al: Vasculogenesis and angiogenesis in embryonic-stem-cell-derived embryoid bodies. Development 102: 471-478, 1988.

13. Wang R, Clark R and Bautch VL: Embryonic stem cellderived cystic embryoid bodies form vascular channels: an in vitro model of blood vessel development. Development 114: 303-316, 1992.

14. Li X and Claesson-Welsh L: Embryonic stem cell models in vascular biology. J Thromb Haemost (Suppl) 1: 53-56, 2009.

15. Descamps B and Emanueli C: Vascular differentiation from embryonic stem cells: novel technologies and therapeutic promises. Vascul Pharmacol 56: 267-279, 2012.

16. Kawamura H, Li X, Goishi K, et al: Neuropilin-1 in regulation of VEGF-induced activation of $\mathrm{p} 38^{\mathrm{MAPK}}$ and endothelial cell organization. Blood 112: 3638-3649, 2008.

17. Han HJ, Heo JS and Lee YJ: Estradiol-17beta stimulates proliferation of mouse embryonic stem cells: involvement of MAPKs and CDKs as well as protooncogenes. Am J Physiol Cell Physiol 290: C1067-C1075, 2006.

18. Heo JS, Lee YJ and Han HJ: EGF stimulates proliferation of mouse embryonic stem cells: involvement of $\mathrm{Ca}^{2+}$ influx and p44/42 MAPKs. Am J Physiol Cell Physiol 290: C123-C133, 2006.

19. Kim GD, Rhee GS, Chung HM, Chee KM and Kim GJ: Cytotoxicity of 5-fluorouracil: effect on endothelial differentiation via cell cycle inhibition in mouse embryonic stem cells. Toxicol In Vitro 23: 719-727, 2009.
20. Kim GD, Bae SY, Park HJ, Bae K and Lee SK: Honokiol inhibits vascular vessel formation of mouse embryonic stem cell-derived endothelial cells via the suppression of PECAM and MAPK/mTOR signaling pathway. Cell Physiol Biochem 30: 758-770, 2012.

21. Ho JW and Jie M: Pharmacological activity of cardiovascular agents from herbal medicine. Cardiovasc Hematol Agents Med Chem 5: 273-277, 2007.

22. Amblard F, Govindarajan B, Lefkove B, et al: Synthesis, cytotoxicity and antiviral activities of new neolignans related to honokiol and magnolol. Bioorg Med Chem Lett 17: 4428-4431, 2007.

23. Park J, Lee J, Jung E, et al: In vitro antibacterial and antiinflammatory effects of honokiol and magnolol against Propionibacterium sp. Eur J Pharmacol 496: 189-195, 2004.

24. Tsai YC, Cheng PY, Kung CW, et al: Beneficial effects of magnolol in a rodent model of endotoxin shock. Eur J Pharmacol 641: 67-73, 2010

25. Park JB, Lee MS, Cha EY, et al: Magnolol-induced apoptosis in HCT-116 colon cancer cells is associated with the AMP-activated protein kinase signaling pathway. Biol Pharm Bull 35: 1614-1620, 2012.

26. Chuang TC, Hsu SC, Cheng YT, et al: Magnolol down-regulates HER2 gene expression, leading to inhibition of HER2-mediated metastatic potential in ovarian cancer cells. Cancer Lett 311: $11-19,2011$

27. Lin SY, Liu JD, Chang HC, Yeh SD, Lin CH and Lee WS: Magnolol suppresses proliferation of cultured human colon and liver cancer cells by inhibiting DNA synthesis and activating apoptosis. J Cell Biochem 84: 532-544, 2002.

28. Park EJ, Zhao YZ, Na M, et al: Protective effects of honokiol and magnolol on tertiary butyl hydroperoxide- or D-galactosamineinduced toxicity in rat primary hepatocytes. Planta Med 69: 33-37, 2003.

29. Heuer J, Bremer S, Pohl I and Spielmann H: Development of an in vitro embryotoxicity test using murine embryonic stem cell cultures. Toxicol In Vitro 7: 551-556, 1993.

30. Scholz G, Pohl I, Genschow E, Klemm M and Spielmann H: Embryotoxicity screening using embryonic stem cells in vitro: correlation to in vivo teratogenicity. Cells Tissues Organs 165: 203-211, 1999.

31. Jakobsson L, Kreuger J, Holmborn K, et al: Heparan sulfate in trans potentiates VEGFR-mediated angiogenesis. Dev Cell 10: 625-634, 2006.

32. Newman PJ: The biology of PECAM-1. J Clin Invest 99: 3-8, 1997.

33. Sauer H, Rahimi G, Hescheler J and Wartenberg M: Effects of electrical fields on cardiomyocyte differentiation of embryonic stem cells. J Cell Biochem 75: 710-723, 1999.

34. Sauer $\mathrm{H}$ and Wartenberg $\mathrm{M}$ : Reactive oxygen species as signaling molecules in cardiovascular differentiation of embryonic stem cells and tumor-induced angiogenesis. Antioxid Redox Signal 7: 1423-1434, 2005.

35. Karar J and Maity A: PI3K/AKT/mTOR pathway in angiogenesis. Front Mol Neurosci 4: 51, 2011.

36. Olsson AK, Dimberg A, Kreuger J and Claesson-Welsh L: VEGF receptor signalling-in control of vascular function. Nat Rev Mol Cell Biol 7: 359-371, 2006.

37. Sato Y: The vasohibin family: a novel family for angiogenesis regulation. J Biochem 153: 5-11, 2013.

38. Frampton JE: Ranibizumab: in diabetic macular oedema. Drugs 72: 509-523, 2012.

39. Hong SW, Jung KH, Lee HS, et al: SB365 inhibits angiogenesis and induces apoptosis of hepatocellular carcinoma through modulation of PI3K/Akt/mTOR signaling pathway. Cancer Sci 103: 1929-1937, 2012.

40. Hong SW, Jung KH, Lee HS, et al: Apoptotic and anti-angiogenic effects of Pulsatilla koreana extract on hepatocellular carcinoma. Int J Oncol 40: 452-460, 2012.

41. Nishikawa T, Tsuno NH, Okaji Y, et al: The inhibition of autophagy potentiates anti-angiogenic effects of sulforaphane by inducing apoptosis. Angiogenesis 13: 227-238, 2010.

42. Xu HL, Tang W, Du GH and Kokudo N: Targeting apoptosis pathways in cancer with magnolol and honokiol, bioactive constituents of the bark of Magnolia officinalis. Drug Discoy Ther 5: 202-210, 2011.

43. Simon HU, Haj-Yehia A and Levi-Schaffer F: Role of reactive oxygen species (ROS) in apoptosis induction. Apoptosis 5: 415-418, 2000

44. Xia Z, Dickens M, Raingeaud J, Davis RJ and Greenberg ME: Opposing effects of ERK and JNK-p38 MAP kinases on apoptosis. Science 270: 1326-1331, 1995. 
45. McCubrey JA, Steelman LS, Chappell WH, et al: Roles of the Raf/MEK/ERK pathway in cell growth, malignant transformation and drug resistance. Biochim Biophys Acta 1773: 1263-1284, 2007.

46. Cho DH, Choi YJ, Jo SA, et al: Troglitazone acutely inhibits protein synthesis in endothelial cells via a novel mechanism involving protein phosphatase 2A-dependent p70 S6 kinase inhibition. Am J Physiol Cell Physiol 291: C317-C326, 2006.

47. Manning BD and Cantley LC: AKT/PKB signaling: navigating downstream. Cell 129: 1261-1274, 2007. 